\title{
CON MANUEL REVUELTA GONZÁLEZ EN ROMA Y ALCOVER (1889-2019)
}

\author{
JOSÉ ANDRÉS-GALLEGO1
}

\begin{abstract}
RESUMEN: El recuerdo de un encuentro en Roma con Manuel Revuelta me lleva a reconsiderar la forma de estudiar las peregrinaciones que se multiplicaron en los siglos XIX y XX. Al rehacer la de Alcover (Cataluña) de 1889 como andadura física de una multitud, aparecen comportamientos que no tienen que ver con la ideología de los organizadores, el "integrismo". Eso me lleva recordar los planteamientos de Victor Turner y la invención de lo cotidiano de que hablaba Michel de Certeau. Me pregunto sobre lo que esa perspectiva plural añade a la historia clásica y nos acerca más a la realidad.
\end{abstract}

PALABRAS CLAVE: Peregrinaciones; invención de lo cotidiano; mentalidad; integrismo.

\section{With Manuel Revuelta González in Rome and Alcover (1889-2019)}

ABSTRACT: The memory of a meeting in Rome with Manuel Revuelta leads me to reconsider how to study the pilgrimages that multiplied in the nineteenth and twentieth centuries. When we remake that of 1889 Alcover (Catalonia, Spain) as a physical journey of a crowd, behaviors appear that have nothing to do with the ideology of the organizers, a fundamentalism (the "integralism"). This also leads me to remember Victor Turner's approaches and Michel de Certeau's invention of the quotidian. I wonder what that plural perspective adds to classical history and brings us closer to reality.

KEY WORDS: Pilgrimages; invention of the everyday; mentality; integralism.

Lo primero que desearía advertir es que, si por mí fuera, no hablaría de Manuel Revuelta en un tono académico, y eso porque ya hace muchos años que los dos superamos la barrera de la relación profesional y nos hicimos amigos.

Sin embargo, el academicismo indispensable lo emplearé para decir formalmente que se nos ha ido uno de los mejores historiadores con que

1 Universidad CEU San Pablo y CSIC (Instituto de Historia). Correo electrónico: 1848jag@gmail.com.

Vol. 78 (2020), núm. 152

MISCELÁNEA COMILLAS

pp. $441-451$ 
contábamos. Digo «historiadores», sin acotarlo de momento, porque su formación humanística no se ceñía a los campos en los que trabajó con más empeño (la historia de la Compañía de Jesús en los últimos siglos; la historia de la Iglesia, sobre todo en España; en definitiva, lo que suele llamarse «Historia contemporánea»). Sus escritos — también los que trataban de esos grandes temas - rezumaban amplitud de horizonte, además de una justeza en la manera de decir las cosas, un equilibrio al tiempo gramatical y personal que se ponía de relieve en sus escritos igual que en sus costumbres y en su modo de hablar.

No sé por qué me viene a la cabeza el día en que le llamé a eso de las tres y media o las cuatro de la tarde y le desperté. No me ocultó que le había despertado ni la sorpresa que le di con ello; jovialmente, me explicó que lo que llamó «la siesta del fraile» era (o es) una institución que debía considerarse casi un requisito canónico no sólo a practicar, sino, como contrapartida, a respetar.

Hace también porción de años que, cuando supo que trataba con él, Quintín Aldea me comentó que me fiara enteramente de Manuel Revuelta. Lo que me sorprendió es que, en el mismo nivel de otras prendas personales que puso de relieve, me dijo que es que era de Palencia y que, en Palencia, la gente es buena. Se me quedó grabado como un criterio que coincidía, es verdad, con mi propia percepción, pero que, en la prosapia sentenciosa y bien intencionada de Quintín, tenía ribetes de norma de conducta. Desde entonces, siempre que conocí a algún palentino, no dudé en partir de ese supuesto y, la verdad, no me he arrepentido. Uno no es palentino, sino aragonés; pero lo cortés no quita lo valiente y las cosas son como son.

Una vez, me dio Manuel (te llamaba Manolo, pero no voy a trivializar lo que sigue con la apariencia de que no va a ninguna parte), me dio, digo, sin quererlo, una lección que, para mí, fue importante, sin duda por lo lejos que estaba de suponer que la realidad era como él me dijo en aquella ocasión. Fui a Roma a no sé qué (siempre hay razones para emprender un viaje a Roma) y pasé a saludar a Pedro como suelo hacer siempre cuando voy por allí. Y bien, la basílica de San Pedro hervía en multitudes; la invadía un sinfín de grupos de muy distinta envergadura, vestidos de todos los colores y, sobre todo, hablando en voz muy alta. Parecía un bazar sin tiendas; la gente caminaba de un altar a otro, cámara fotográfica en ristre, y cada cual llamaba la atención —no digo a gritos, pero cerca estaban- de lo que los demás pasaban de largo.

No peco de puritano ni pacato, ni soy buen rezador; pero me indigné; me acordé de la expulsión de los mercaderes del templo y, si en mi mano hubiera estado, habría sugerido a la guardia vaticana que desalojase la feria. Di la 
vuelta al enorme templo con la resignación del impotente y, al doblar una esquina, me encontré con Manuel; andaba con visible tranquilidad, despacio, y daba la impresión de que oía aquella algarabía, pero no la escuchaba, iba vuelto sobre sí mismo; adiviné que rezaba el rosario recogido en la intimidad de aquel bullicio. Hablamos un momento y le expuse mis quejas, y hete aquí que me respondió con lo que menos esperaba; me dijo que la gente sencilla manifestaba así la fe. No le hizo falta adoctrinarme; fue un primer paso para aprender una lección que aún tarde en asimilar. Lo más claro de la lección es que no hay que juzgar. El añadido de que, además, uno será juzgado con la misma medida con que juzgue es, sin lugar a duda, definitivamente disuasorio. Pero la realidad que puso de relieve aquella reflexión de mi amigo es mucho más profunda, uno diría que insondable.

He recordado muchas veces la lección de aquel día; la última vez, por cierto, al estudiar a un personaje por quien sentía él una notable admiración, Francisco Butiñá. En 1889, hacía pocos meses que los carlistas se habían desprendido de los «íntegros» -un asunto que Manuel Revuelta González conocía muy bien, y no digamos su estudiado Luis Martín, que no era palentino, sino burgalés, pero de Melgar de Fernamental, que está a medio camino de las dos ciudades, y, por tanto, era hombre bueno en calidad de medio palentino.

El caso es que, por entonces (1889), se habían convertido en un fenómeno frecuente las peregrinaciones multitudinarias, a ser posible a Roma y a pedir por «el prisionero del Vaticano», y los «íntegros» se habían hecho con la iniciativa de organizar una en España para conmemorar el centenario de la declaración de fe de Recaredo en el III Concilio de Toledo. Los carlistas no secundaron la iniciativa por ser del enemigo, y mosén Cinto —-sí, el gran poeta catalán y en catalán- terció y propuso que se peregrinara para celebrar ese hecho, que era el realmente importante y el que debía unir a todos.

Y así se hizo. Sólo que la prudencia aconsejó que no se convocara una manifestación nacional, sino que, en cada diócesis, se las arreglara el obispo. Así, si había enfrentamientos, quedarían en quimera comarcal. El jesuita Francisco Butiñá — que era «íntegro»— se hallaba entonces en la comunidad de Tarragona, y en la sede primada, se acordó concentrarse en la villa de Alcover y caminar la media hora escasa que hace falta para llegar a la ermita del Remey (se entiende que de la Virgen del Remedio).

En un volumen académico como es éste, libertad de cátedra y expresión se da por descontado y una de las cosas que en su día encontré en el archivo del cardenal Gomá —otro tarraconense- era el informe histórico aducido bajo su autoridad para defender la primacía toledana. Y bien, tras un maduro examen, hace tiempo que concluí que sólo los españoles (en el mundo) 
tenemos el notable privilegio de que nuestro primado - el de Toledo- no se siente en la sede primada, que es la de Tarragona (salvo mejor criterio).

He estudiado la peregrinación de Alcover de 1889 con el mayor detenimiento al rehacer la biografía de Francisco Butiñá y creo que a Manolo le gustará saber cuál es mi conclusión más importante; el jesuita Butiñá fue de los pocos eclesiásticos que tomaron parte en la romería, y la diversidad y cantidad de los relatos periodísticos que provocó permite rehacer con detalle el proceso de formación y desarrollo de un evento como ese en diversos niveles.

Verán. Quien está acostumbrado a ir a entierros en pueblos de montaña, sabe muy bien que delante va el monaguillo con la cruz, tras él el sacerdote si solo asiste uno, cerca de él el ataúd con el cadáver, unas veces a hombros y otras en la parte de atrás de un haiga funerario, a continuación los parientes más próximos, los que llevan las flores - las coronas que los católicos españoles de 1889 no veían con buenos ojos, como el símbolo de la Roma pagana que encontraban en ellas-y después la larga comitiva de los deudos y amigos.

Si Manuel hubiese asistido a encuentros como ese, no le habría extrañado que, a partir de la segunda o cuarta fila, los rezos dejen paso al silencio y, enseguida, el silencio a la conversación, de manera que la mitad de los acompañantes - como poco-comentan el último partido o el precio del cereal o del ganado. ¿Me diría Manuel que es que la gente sencilla reza de esa manera a Dios o, mejor, no reza propiamente, sino que expresa así su más sincera -y religiosa- compañía a la mortaja?

Lo que no me pregunto es si interpretaría de la misma manera lo que encontré en la peregrinación a Alcover de hace ciento treinta años largos; probablemente, sí. Sucedió algo que media entre los cortejos fúnebres de montaña a que me he referido y la visión de José Pla de la quema de los conventos de 1931 en Madrid; si, en estos, el calor de la quema y la pasividad de los transeúntes quedó firmada y rubricada cuando apareció un heladero empujando su carro y dispuesto a vender helados (que, en efecto, vendió), en Alcover no fue pasividad sino la actividad del peregrino la que expresó las formas más diversas de tomar parte en un acto como aquel, que no sólo era religioso, sino, a la vez, político y, simultáneamente, penitencial.

Los organizadores conocían el paño y habían programado las dos misas de rigor en aquellos tiempos: la de comunión a las nueve de la mañana, en la parroquia de la villa, y la solemne al llegar a la ermita, unas horas después. La primera - la celebrada en la parroquia de Alcover-, la dijo el vicario capitular de la diócesis - Francisco Morante y Ramón-y, a Francisco Butiñá le correspondió pronunciar la plática y «hacer fervorines», que era como se designaban las breves exhortaciones al fervor que hacían algunos sacerdotes 
en ocasiones como ésa, al mismo tiempo en que otro oficiaba el acto litúrgico $^{2}$. El templo estaba «de bote en bote» y la comunión duró media hora, a pesar de que la administraron varios sacerdotes ${ }^{3}$. "Inmenso era el gentío que había en la Iglesia parroquial, hasta el extremo de tener que permanecer en la plaza multitud de romeros que no cabieron [sic] en la Iglesia».

Pero es que, además, hubo algunos que no entraron y prefirieron almorzar tranquilamente "paseando por las calles» ${ }^{4}$. Sencillamente, debieron ser los que no querían comulgar y sabían — como todos los demás- que aun habría segunda misa y que, por tanto, cumplirían de esa otra forma con el precepto dominical de oírla y que eso bastaba.

Los relatos de la celebración (organizada y acaparada por los «íntegros») no ocultan hechos como ése que no sabríamos decir si eran carlistas o integristas, liberales o republicanos, incluso católicos o acatólicos. Tras la misa de comunión en la parroquia, se dejó un rato largo para tomar «un tente en pie, sacando provisiones de los sacos de viaje y envoltorios que llevaban consigo» los romeros, como solía hacerse en esos casos. Si se relee lo que hemos dicho anteriormente, para algunos romeros, era el segundo tentempié.

A las diez y cuarto, se formó la procesión para ir andando al santuario, situado en el campo, en un leve altozano, al pie de una colina y a menos de media hora de camino desde la villa ${ }^{5}$. Ahora, el que presidía aquel río de gente peregrina era el párroco, con el vicario capitular a la derecha y el arcediano de la catedral de Tarragona — el doctor Pablo Forés- a la izquierda, que había acudido al menos con otros dos canónigos, Salas y Ródenas por nombre ${ }^{6}$. El doctor Pablo Forés era hombre que había llamado la atención especialmente en 1869, tras la revolución de septiembre, cuando manifestó que su condición de eclesiástico no le permitía jurar la constitución aprobada ese año y, en consecuencia, fue expulsado de la Comisión de Monumentos

2 Lo de los fervorines, en el horario previsto que publicó (Domingo, 23 de junio de 1889). El Eco de Valls: Periódico político de avisos y noticias: Órgano del partido Liberal del distrito de Valls-Montblanch: Se publica los jueves y domingos, VII, n ${ }^{\circ}$ 51, 2. Los datos de la misa y lo que sigue, asimismo (Jueves, 4 julio de 1889), VII, $n^{\circ} 54,2$, salvo cuando citemos expresamente otra fuente.

3 Romería a la Virgen del Remedio de Alcover. (Martes, 2 de julio de 1889). La Opinión: Eco del Partido Liberal-Dinástico de la Provincia: Diario de avisos y noticias (Tarragona), XV, $\mathrm{n}^{\circ} 275,2$.

4 En Tarragona = Romería. (Martes, 2 de julio de 1889). La Provincia: Diario político, de avisos y noticias (Tarragona), I, $\mathrm{n}^{\mathrm{o}} 76,1$.

5 (Jueves, 4 julio de 1889). El Eco de Valls..., VII, n ${ }^{\circ}$ 54, 2.

6 Tatató (martes, 2 de julio de 1889). Correspondencia = Tarragona $1^{\circ}$ de Julio de 1889. El Mercantil: Diario político de avisos y noticias: órgano del Partido Liberal de la provincia de Tarragona, III, nº 153, 2. El segundo debía ser Juan Ródenas y Perona, canónigo entre 1875 y 1896. 
de Tarragona (el organismo oficial que había en todas las provincias para impulsar el estudio y cuidado de su patrimonio monumental) (Maier Allende, 2007, p. 122).

El relato de uno de los testigos de aquella romería, la del Remey de Alcover en 1889, nos permite contemplar un boceto casi plástico de lo que era una de estas concentraciones: los peregrinos marchaban «en agrupaciones de pueblos y asociaciones, con sus pendones y estandartes, y entonando cánticos religiosos. Iban en número de cerca de cuatro mil (en inmensa mayoría, mujeres); todos ostentaban escapulario y llevaban pertrechos de boca, incluso el botijo algunos hombres ${ }^{7}$ (y veremos que también bota, o sea — presuntamente- vino). Los estandartes pasaban de cincuenta, precisaría el redactor de La Opinión.

Pero no tardó en hacerse notar el calor del primer verano:

Eran ya las diez de la mañana y, por lo tanto, los ardientes rayos del sol se dejaban sentir con toda su fuerza y, sin embargo, las márgenes del camino, desde el pueblo a la indicada hermita [sic], se hallaban llenas de gente ávida de ver la procesión para trasladarse después al Santuario.

Algunos vecinos de Alcover habían sido previsores y pusieron algunas mesas con refrescos o pura y simple agua para aliviar a los romeros ${ }^{8}$ no sabemos si gratis y si no se oponían a que el consumidor dejase una moneda). Funcionalmente, no hicieron otra cosa que lo que haría el heladero que nombramos ante el calor que producía la quema de conventos medio siglo después.

El corresponsal de El Mercantil advertiría que procesionar, lo que se dice procesionar, de los vecinos de Alcover, sólo lo hizo «una docena escasa» ${ }^{9}$. A lo mejor sabían que el calor apretaría aún más. «A pesar de llevar los romeros, sombrillas y paraguas, imposible era resguardarse de los ardientes rayos de un sol verdaderamente tropical». "La ascensión por la montaña fue penosa, sudando a mares los romeros» (y eso a pesar de que el desnivel desde la plaza de Alcover hasta la ermita no pasaba ni pasa de setenta metros de altura). «Mala hora la elegida y mala la estación: así sería obra más meritoria la de los

7 (Jueves, 4 julio de 1889). El Eco de Valls..., VII, $\mathrm{n}^{\circ}$ 54, 2.

8 Romería a la Virgen del Remedio de Alcover. (Martes, 2 de julio de 1889). La Opinión: Eco del Partido Liberal-Dinástico de la Provincia: Diario de avisos y noticias (Tarragona), XV, n 275, 2. Se añade lo del agua en En Tarragona = Romería. (Martes, 2 de julio de 1889). La Provincia: Diario político, de avisos y noticias (Tarragona), I, $\mathrm{n}^{\mathrm{o}} 76,1$.

9 Tatató (martes, 2 de julio de 1889). Correspondencia = Tarragona $1^{\circ}$ de Julio de 1889. El Mercantil: Diario político de avisos y noticias: órgano del Partido Liberal de la provincia de Tarragona, III, $\mathrm{n}^{\circ} 153,2$. 
peregrinos ${ }^{10}$, y eso por más que los hubiera tan precavidos que —según $L a$ Opinión de Tarragona- llevaban tiendas de campaña (sic) que procedieron a montar al llegar a la ermita, a fin de resguardarse del sol. Además, «sacaron las provisiones que llevaban y, como había buen apetito, pues el camino se hizo algún tanto pesado, empezaron a comer tranquilamente en medio de la general alegría que reinaba en todos aquellos alrededores». Tercer tentempié.

Como el templo se halla al pie de la colina y bajan varios arroyuelos, hubo agua fresca suficiente, lo cual no obstaba sin embargo para empinar la bota como se vería enseguida y en circunstancias tan significativas y dignas de respeto y moderación como la mismísima Eucaristía.

En la plazoleta que hay delante del templo, se había habilitado un altar, entoldado con ramaje espeso, y, separado de él, a la entrada de la plaza, habían alzado un púlpito para la ocasión. Hubo misa solemne al aire libre, por tanto, que comenzó a las doce. Y, si al echar a andar la procesión, el cronista de El Eco de Valls había calculado cuatro mil personas, en la misa y alrededores el redactor de La Opinión cifraba en siete mil los asistentes, como el de La Provincia, quien añadía que se extendían desde lo alto de la colina hasta el fondo del valle -escaso valle-, todo lo cual, para su bien, lo cubrían «corpulentos árboles», más los algarrobos, olivos y aún más de otras especies que sembraban la parte baja.

"Todo era animación», añade, "todo alegría y, sin embargo, ni un solo desorden, ni una sola palabra se dijo que pudiera ofender a persona alguna, y era tal el aspecto que presentaba que decían los ancianos de Alcover no haberse visto espectáculo igual» ${ }^{11}$.

Quien ofició en el santuario fue el párroco de Alcover en compañía de otros dos sacerdotes. "[La] misa fue cantada a toda orquesta por la capilla que dirige el R[everen]do don Ramón Bonet». El sagastino redactor no parece dorar la píldora, a juzgar por lo que alabó: «Daba gusto en verdad», escribió, «observar cómo, con los cantos de la capilla, se confundían en amigable consorcio los gritos de expansión de los romeros que continuaban fortaleciendo su estómago para resistir mejor después el viaje de regreso» ${ }^{12}$. ¿Era ya el cuarto tentempié?

Eso, el liberal dinástico de La Opinión de Tarragona; porque el de El Eco de Valls —igualmente liberal_ dio un detalle revelador, si es que, puesto a

\footnotetext{
10 (Jueves, 4 julio de 1889). El Eco de Valls..., VII, no $54,2$.

11 En Tarragona = Romería. (Martes, 2 de julio de 1889). La Provincia: Diario político, de avisos y noticias (Tarragona), I, $\mathrm{n}^{\circ} 76,1$.

12 Romería a la Virgen del Remedio de Alcover. (Martes, 2 de julio de 1889). La Opinión: Eco del Partido Liberal-Dinástico de la Provincia: Diario de avisos y noticias (Tarragona), XV, n ${ }^{\circ}$ 275, 2.
} 
renglón seguido de lo que dejó escrito sobre la santa misa, tuvo lugar durante la celebración, como parece y anunciábamos: «Los romeros, diseminados por debajo [de] los árboles, en tanto, levantaban a menudo la bota, porque el calor convidaba a ello» ${ }^{13}$. Era, en efecto, el cuarto tentempié.

Si fue cosa del calor, hay que tenerlo en cuenta, desde luego, aunque sea como atenuante. Recuérdese además que ya habían oído misa y, en su caso, comulgado; de manera que sólo puede interpretarse como un comportamiento eminentemente pragmático, desprovisto, eso sí, de preocupaciones que unieran ascesis y rubor ${ }^{14}$. En el horario de Alcover y 1889 estaba previsto que, a continuación, varias personas — varones eclesiásticos todas, se desprende- se dirigieran a los romeros. Pero sólo lo hizo, por fortuna -dado el calor que hacía-, mosén Boqueras, rector de una de las parroquias de Reus y, además, «no fue largo y terminó con un viva a la Virgen del Remedio, otro a la Unidad Católica, otro al Sagrado Corazón de Jesús y otro al Santísimo Padre León XIII» ${ }^{15}$.

También se preveía que la gente comiera por allí y, a las tres de la tarde, hubiera un acto de despedida y consagración a la Santísima Virgen y, en procesión de nuevo, regresaran al pueblo, a la iglesia parroquial. Pero el regreso se inició a las dos, una hora antes de lo que habían previsto ${ }^{16}$. Sin duda, ya les había bastado con lo ingerido en las tiendas de campaña o a la sombra de un árbol.

No parece que se volviera en procesión, aunque acabara por formarse. «Después [del breve exordio de mosén Boqueras], empezaron ya algunos romeros a trasladarse a Alcover, cuyas calles se hallaban asimismo llenas de gente, sin importarles poco ni mucho pasear por ellas comiendo un buen trozo de butifarra [sic], y las peregrinas buscaban también con asiduidad y avidez dónde encontrar alguna bebida que aumentara sus fuerzas, sin preguntarse si era o no era el quinto tentempié de la jornada».

«Después, trasladóse la peregrinación a la iglesia de Alcover, también en procesión, y, llegada que hubo» (a las tres ${ }^{17}$ ), «se cantó a toda orquesta el Seráfico Trisagio con exposición de S[u] D[ivina] M[ajestad]»; debió de hacerse un acto de desagravio — porque estaba programado— y el jesuita Jaime

13 (Jueves, 4 julio de 1889). El Eco de Valls..., VII, no 54, 2.

14 (Jueves, 4 julio de 1889). El Eco de Valls..., VII, no 54, 2.

15 Romería a la Virgen del Remedio de Alcover. (Martes, 2 de julio de 1889). La Opinión: Eco del Partido Liberal-Dinástico de la Provincia: Diario de avisos y noticias (Tarragona), XV, $\mathrm{n}^{\circ} 275,2$.

16 (Jueves, 4 julio de 1889). El Eco de Valls..., VII, no 54, 2.

17 Este detalle, en En Tarragona = Romería. (Martes, 2 de julio de 1889). La Provincia: Diario político, de avisos y noticias (Tarragona), I, $\mathrm{n}^{\circ}$ 76, 1 . 
Maresma pronunció un sermón breve ${ }^{18}$ y se supone que el vicario capitular —o alguien en quien acaso delegó- cumplió con el propósito de impartir la bendición apostólica, que se había pedido y conseguido de León XIII para aquella ocasión.

En todo caso, la función acabó con el cántico Ruja el infierno, del organista y compositor Cándido Candí y letra de Félix Sardá y Salvany, ya autor famoso del que iba a ser uno de los best-sellers de la literatura hispana del siglo XIX, El liberalismo es pecado.

En todos los actos litúrgicos del día, se había preferido cantar Corazón santo, tú reinarás ${ }^{19}$. Pero, a esa altura de la historia, ya se imponía algo más expresivo. No es menos expresivo que algunas otras cosas que acabamos de ver, la paulatina aproximación a la «expresividad» de que hablo por parte de quienes se refirieron a los cánticos; el redactor de La Opinión dijo que habían preferido cantar durante el día Firme la voz (que era como empezaba la canción que había compuesto Sardá y Salvany; pero los menos comedidos la llamaban Ruja el infierno, que era como empezaba el estribillo. Se había difundido en la peregrinación a Roma de 1876 y decía así:

Firme la voz, serena la mirada, del mundo en faz, cantemos nuestra fe:

De Cristo Dios, la Iglesia es nuestra Madre;

de Roma, el Rey cautivo es nuestro Rey.

¡Antes morir que separarnos de él!

Del pueblo hispano, noble y leal

aqueste grito siempre será:

¡Ruja el infierno, brame Satán!

¡La fe de España no morirá!

Me cuidaré muy mucho de ironizar sobre este ripio y me resistiré a cualquier análisis teológico que pueda llamar la atención sobre cosas tan serias, por ejemplo, como el reconocimiento de la autoridad temporal del prisionero del Vaticano que se manifiesta en el cuarto verso.

Lo que no me parece desdeñable es lo que pone de relieve ese relato; los expertos en historia de las peregrinaciones católicas han destacado — con toda la razón- cómo se convirtieron en instrumento ideológico y partidista en la segunda mitad del siglo XIX. Y aquella de Alcover lo ratifica. Pero, al

18 Romería a la Virgen del Remedio de Alcover. (Martes, 2 de julio de 1889). La Opinión: Eco del Partido Liberal-Dinástico de la Provincia: Diario de avisos y noticias (Tarragona), XV, n $275,2$.

19 Todo esto en (Domingo, 23 de junio de 1889). El Eco de Valls..., VII, no 51, 2; (Jueves, 4 de julio de 1889). El Eco de Valls..., VII, nº 54, 2. 
mirar hacia los feligreses, no hemos visto más ideología propiamente política que la sentencia de que, «de Roma, el Rey cautivo es nuestro Rey».

Habría más seguramente; pero ni siquiera ésa llamó la atención de los periodistas. Y, en cambio, sí lo hicieron detalles que se pueden poner en relación con la algarabía que había un centenar de años después en San Pedro del Vaticano, cuando me encontré con Manuel Revuelta (con la muy importante diferencia de que, en esta ocasión, no se veían botas ni botijos no se puede afirmar que la gente se alimentara).

Lo serio del asunto es que todo esto forma parte de la historia que los expertos - me parece a mí- deberían considerar relevante; no me cabe la menor duda. Años antes de aquel encuentro, había hecho la tesis doctoral sobre la cuestión religiosa en la España de 1899 en adelante como expresión palpable de las dos Españas -el mito que servía para explicarlo todo-; era mi primera investigación. Pues bien, al mes de comenzar (lo recuerdo muy bien), empecé a pensar que aquellas no pasaban de ser dos minorías que se peleaban de vez en cuando y que las dos «Españas» no aparecían por parte alguna. Enlacé así, con lo que vi enseguida que concluían, sobre la pasividad de los españoles, los historiadores que se empezaban a formar en el Iberian Center de Oxford, Romero Maura a la cabeza, y, a estudiar eso -la «desmovilización» de los españoles-, dediqué buena parte de los años que siguieron.

La lección de Manuel Revuelta dio, a mi entender, un paso más, y es que esa pasividad esconde — a veces - verdaderas acciones, que no tenían nada de pasivas; eran actividades que, simplemente, se orientaban de distinta manera a como habían sido concebidas (y quizá vividas por otros). Si hubiera espacio, a gusto intentaría desarrollar todo esto y compararlo con la perspectiva que los antropólogos nos ofrecen a los historiadores, sobre todo tras las huellas de Victor Turner (1974, pp. 166-230) tal como las siguieron Ashley (1990), Cohen (1992), MacClancy (1994) y varios más. Con otro jesuita, Michel de Certau, cabría considerarlo como «la invención de lo cotidiano», y es que la gente — quizá toda la gente; en todo caso, cualquier tipo de gente - tiende a seguir por el camino que le trazan, pero, con no poca frecuencia, lo reinventa, principalmente en el sentido de que le da un destino - una finalidad- que es distinto de aquel para el cual lo crearon y para el que esa misma gente pareció que actuaba.

En el caso de la peregrinación de Alcover, la reinvención debió ser universal, o sea de todos sus aspectos. Porque ni los que promovieron los vivas a la unidad católica ni los que se aliviaban con bota y tentempié —esto es: ni unos ni otros - se acordaron de Recaredo, a juzgar por el silencio que se desprende de los periódicos que explicaron lo sucedido, y eso a pesar de que 
su confesión de fe era lo que había logrado que aquello no fuera ni integrista ni carlista ni liberal ni tampoco republicano.

Analizar así los hechos históricos es enormemente revelador. Se adecúa mejor al carácter tragicómico de la vida, que es distinta en cada momento según la dosis de tragedia y la dosis de comedia con que podemos tamizarla.

Nos descubre lo implícito de forma más veraz que el taimado método de la sospecha (que es otra forma de interpretar procesos inconscientes). En la sospecha hay un pre-juicio, un juicio previo, y la investigación sólo sirve para descubrir lo que ya sabemos o creemos saber; en la búsqueda de la invención posible de lo cotidiano, el único prejuicio que se puede admitir es que las cosas pudieron ser de otra manera a como las pintaron.

\section{REFERENCIAS}

Ashley, K. M. (1990): Victor Turner and the construction of cultural criticism: Between literature and anthropology. Bloomington e Indianapolis: Indiana University Press.

Cohen, E. (1992). Pilgrimage centers: concentric and excentric. Annals of tourism research, XIX, núm. 1: 33-50 (ref. 14839).

De Certeau, M. (1996): La invención de lo cotidiano. 1: Artes de hacer. Méjico D.F.: Universidad Iberoamericana.

MacClancy, J. (1994). The construction of anthropological genealogies: Robert Hertz, Victor Turner and the study of pilgrimage. Journal of the Anthropology Society of Oxford. XXV, núm. 1: 31-40 (ref. 14840).

Maier Allende, J. (2007). Noticias de antigüedades de las actas de sesiones de la Real Academia de la Historia (1834-1874). Madrid: Real Academia de la Historia, 2007.

Roussel, R. (1972). Les pèlerinages. París: Presses Universitaires de France.

Turner, V. (1974). Pilgrimages as social processes. En V. Turner: Dramas, Fields and Metaphors: Symbolic Action in Human Society, Symbol, Myth and Ritual. Ithaca y Londres: Cornel University Presse. 